\title{
Risky Shift Versus Cautious Shift: Determining Differences In Risk Taking Between Private And Public Management Decision-Making
}

\author{
Douglas B. Reynolds, University of Alaska Fairbanks, USA
}

Jacob Joseph, University of Alaska Fairbanks, USA

Reuben Sherwood, University of Alaska Fairbanks, USA

\begin{abstract}
This paper uses empirical evidence to examine whether people take more risk for their own potential loss/gain and less risk for other people's potential loss/gain or vice versa. An experiment is described wherein participants had the option of taking different risks in exchange for their own benefit and the benefit of others. Results indicate that subjects take a statistically significant higher level of risk for themselves as individuals than they do when other's payoffs are at stake. This indicates that people are less risk averse in making decisions for themselves and more risk averse in making decisions that affect others. However, when the amount of reward is increased, the findings change. The purpose of the experiment is to find a better explanation for how government-owned businesses or large corporations work, where anecdotal evidence suggests much less innovation and risk taking takes place compared to small proprietary firms.
\end{abstract}

Keywords: Risk, Experimental Economics, Investment, Decision Making, Government Ownership

\section{INTRODUCTION}

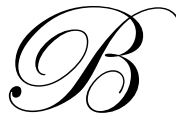

usiness management often involves assessing risk in project investments. One of the more interesting aspects of risk taking compares how much risk small "dynamic" firms take compared to large "stodgy" firms, especially large government-owned firms. The Bureau of Labor Statistics (see Helfand et. al. 2007) for example shows that small firms in proportion to their size have made a bigger contribution to the economy in terms of numbers of new jobs created than have larger firms. One reason small firms may have higher growth rates (and a higher probability of failure) is because there is more risk taking in those firms than in large firms, especially large publicly owned firms. One reason a small firm may take more risk than a large or a government owned firm is because the main decision maker in a small firm is the entrepreneur who is deciding risk for his own loss or gain where as in a large or government firm, the main decision maker is deciding risk for other people's loss or gain. In this paper, we want to investigate how much risk taking individuals actually carry out under two scenarios that may mimic the management decision making of a small private firm versus a large publicly owned firm. One scenario is where participants choose a risky decision for their own benefit. A second scenario is where participants choose a risky decision for the benefit of others.

According to Stoner (1961) the term "risky shift" and "cautious shift" explain changes in risk taking levels. Risky shift refers to a situation where people start at their average level of risk taking, usually a risk averse level, and then due to exogenous circumstances become less risk averse. Cautious shift refers to a situation where people start at their average level of risk taking and then due to exogenous circumstances become more risk averse. This paper uses empirical evidence to examine whether it is true that people are less risk averse for their own potential gains and more risk averse for other people's potential gains, i.e. whether there is a cautious shift or a risky shift in decision making for others compared to oneself. An experiment is described wherein participants had the option of 
taking different risks for different potential gains both for their own benefit and for the benefit of others. Results indicate that subjects have a statistically significant lower level of risk aversion for themselves as individuals than they do when other's payoffs are at stake. This indicates that people exhibit a cautious shift where they are relatively less risk averse in making decisions for themselves and relatively more risk averse in making decisions that affect others. This parallels how business leaders take risk depending on if they are taking the risks for their own gain or if they are taking the risks for other people's gain. Interestingly, even government bureaucrats such as pharmaceutical regulators, who must determine other's risk, can show greater risk aversion when they decide to prohibit new drugs on the market even though these new drugs could save lives but have significant side effects or other unintended consequences including death (Ward 1992).

A second iteration of the experiment provided a higher pay-off. This result found that the higher pay off changed the outcomes so that the cautious shift affect was lost. The change in the cautious shift when higher payoffs were used may be attributable to people becoming more prone to gambling based on early risk taking results. This is explained further in Section 6: Data and Results.

\section{THEORETICAL LITERATURE}

Looking at the literature on risk and how it affects behavior, Stoner (1961), Kogan and Wallach (1964), and Wallach, Kogan, and Bem (1962) proposed the Risky Shift Phenomenon, which explains how individuals, when placed in a group, take more risks than they would otherwise. In other words, a person's normal level of risk taking changes when these same people are in different environments. Specifically people look to take more risks in a group than they would normally do by themselves. The Risky Shift Phenomenon explains why a mob can become unruly, where individuals - prodded by their peers - engage in risky illegal activities in which they would not otherwise participate (see Sorrentino et. al. 1992). This has been further developed into the Group Polarization Effect by Levine and Moreland (1998) where groups can be pushed by a dominant personality to become more risk loving or more risk averse in certain situations.

The problem with the literature on risky shift and group polarization is that they emphasize decisions made in public by a spontaneous grouping whereas many decisions made in business within a large corporation or by a government-owned entity are likely to be deliberated and decided upon in private by an individual or a small group. Business decisions are usually not deliberated and decided upon in a public setting with a lot of fanfare. Where the decision making entity is isolated, the entity may become more risk averse if it is making decisions that mostly benefit others rather than itself. To put it in another way, this may result in a cautious shift rather than a risky shift.

Interestingly, Stoner originally was trying to prove that people would exhibit a cautious shift rather than a risky shift, since he believed that people would become more cautious when making decisions in front of a group. Stoner's motivation is based on an anecdote by General James M. Gains who evaluated military generals throughout history and their decisions to take risks. As each general takes on more responsibility, the risk taking level is reduced. For example Kowert and Hermann (1997) note that high ranking generals, who were identified as vacillating in their later careers, were noted for their daring and determination as junior officers. While the relationship could be due to age and experience, it could also be because of the greater responsibility and public accounting which coincide with achieving a higher rank. Thus it seems that as individuals take on greater responsibility they exhibit a cautious shift and this may affect business decision making as well.

The idea of the cautious shift does show some validity in business. March and Shapira (1987) show that company managers may shift their level of risk taking depending on circumstances. Swalm (1966) shows that managers appear to have an excessive aversion to any outcome that could yield a net loss. This is not simply loss aversion, which is simply to eschew projects with low expected values, but rather it is risk aversion where managers refrain from projects that have wide probability distributions. Viscusi et. al. (1987) conclude that managers are extremely reluctant to accept responsibility where there is even a small increase in the probability of a disaster. Miller and Ross (1975) argue that managers assess risk based on the worst possible outcome. Kahneman and Lavallo (2002) suggest that managers tend to make bold forecasts and yet take timid choices. Also Kahneman and Tversky's (2002) research shows that individuals over-emphasize extreme outcomes. 
In the case of a government-owned oil company, Ramsey (1980) shows interesting results that an asymmetry may exist whereby a business loss by a government company could result in a larger decline in the constituents' utility than an analogous gain would raise it. This may be due to the fact that increased government revenue would be subdivided into a myriad of different projects, effectively diluting whatever benefits the extra profits give. On the other hand, losses generated by a government-owned oil company have a clear impact — higher taxes or program cuts - and the constituents may feel that their tax money had been wasted on a questionable endeavor. This asymmetry in utility changes for gains and losses of national income follows Friedman and Savage (1948) and Markowitz (1952) ideas of utility and Khaneman and Tversky's (2002) prospect theory and is a political consideration that may make monopoly national oil companies more risk averse than private enterprises.

The difference between Stoner's risky shift and alternative arguments for a cautious shift may have to do with how much money is on the line or in the case of generals how many lives are on the line. For example, Holt and Laury (2002 and 2005) show an increase in risk aversion with increasing payments. Another difference as mentioned is that the decisions about risk in Stoner's experiment are made in front of a group; while decisions in business are often made in isolation and then revealed only after the results are apparent. Thus a business manager, unlike Stoner's subjects, must make in private those risky decisions that affect corporate stockholders realizing that the results will be revealed later. If politically there is a strong likelihood that negative outcomes are going to have a greater weight than positive outcomes, managers, who often make decisions in private, are more apt to take a cautious shift in decision making than a risky shift in comparison to their own personal level of risk taking.

\section{SOME EXPERIMENTAL LITERATURE}

Looking at the experimental literature on risk taking, Holt and Laury (2002), Harrison et. al. (2005a), Holt and Laury (2005), Chakravarty et. al. (2005) and Harrison et. al. (2005b) all use a similar approach to measuring risk taking by having individuals make a set of decisions incrementally from one side of a risk taking scenario to another. In general Holt and Laury find that subjects are risk averse and that increased incentives increase risk aversion by test subjects. Chakravarty et. al. find that people are highly risk averse when choosing risk for themselves, but that when subjects make anonymous choices for others they are less risk averse. Therefore, the Chakravarty et. al. results seem to vindicate Stoner's results even though in the Chakravarty experiment the subjects were isolated from the group. Also Harrison et. al. (2005b) shows very little difference in risk preferences between individual decisions for the subjects own gain and individual's anonymous decisions for other's gain.

In the Harrison et. al. (2005b) study even though participants choose for others, it was still a group decision since each participant could only vote for a group's payoff choice. However, the Chakravarty experiment has individuals making independent decisions for others.

The procedures used in these experiments of eliciting a series of decisions that slowly change is rather like a manager of a company that gains experience about what it is like to make a risky decision for oneself and for others. However, it is often the case that a business must make decisions one at a time and that a single decision will be so unique, either in circumstances or in value, in comparison to previous decisions that no amount of experience will help. In those instances, it would be good to test how a single valuable option is decided upon. This is the case that we hope to show here.

Another interesting experimental approach is Charness and Jackson (2007) where participants play a version of Jean-Jacques Roseau's classic stag hunt similar to a prisoner's dilemma game. In the Charness and Jackson version, though, instead of a single player playing each side of the game, a team of 2 players play each side with one team member being the dictator or chief decision maker for the team. In the Charness and Jackson results, unlike the Chakravarty et. al. results, there is more risk aversion for participants making decisions for others in comparison to making such decisions for oneself. 


\section{THE RISK AVERSE MODEL}

Newendorp and Schuyler (2000) show how decision making at the margin works. Figure 1 shows a typical decision rule for making risky choices, where a manager must make a trade off between risk and the rate of return. There are three curves. One curve is a base case "iso-utility" curve. If a person is at point " $\mathrm{B}$ ", then the only way that he will take more risk is if he is compensated with a higher rate of return. Thus his iso-utility curve is upward sloping and concave. However, he will accept a lower rate of return if he is compensated with less risk. The risk taking utility curve is concave because of the law of diminishing marginal utility for preferences. The second curve at point " $\mathrm{A}$ " is exactly like the first except this is the iso-utility curve of a more risk loving entity. What the figure shows is that those who are more risk loving do indeed gain a higher present value — return on investment — whereas those who are more risk averse gain less. The more risk loving people use additional levels of risk taking as an input into production in order to increase their gain. The third curve is the "iso-capital" constraint curve. What this curve shows is that if a company or government-owned entity faces a constraint on the amount of capital that it has available for investment, it must choose between using more or less risk as an input into its investment "production function" to increase present value. The iso-capital constraint curve is convex due to the law of diminishing returns, i.e. the first use of risk creates a huge marginal gain to investment outcomes, but the more risk is used, the lower the marginal gain to risk becomes.

One example of this capital constraint is to imagine that a company has an extra $\$ 100$ million to spend this year and must decide how to invest it. There are three options. One is to invest in a new endeavor, such as a new product line with new manufacturing capacity, which is highly risky but does have a high expected pay off. A second option is to put the money into extra maintenance of existing manufacturing facilities. The extra maintenance will simply give a higher assurance of having no future maintenance problems and therefore reduce future potential costs but have a lower expected payoff. There is also less risk involved. A third option is to give employees a bonus. This will possibly increase morale and encourage harder work or less attrition and create almost no risk of further losses. It may however earn a very low corporate payoff. The capital available for all these investment options is constrained and therefore investing the capital into high risk high return options that can create a higher present value is mutually exclusive to investing it into low risk, low return options.

Figure 1. Risk and Utility maximization given an Iso-Capital constraint

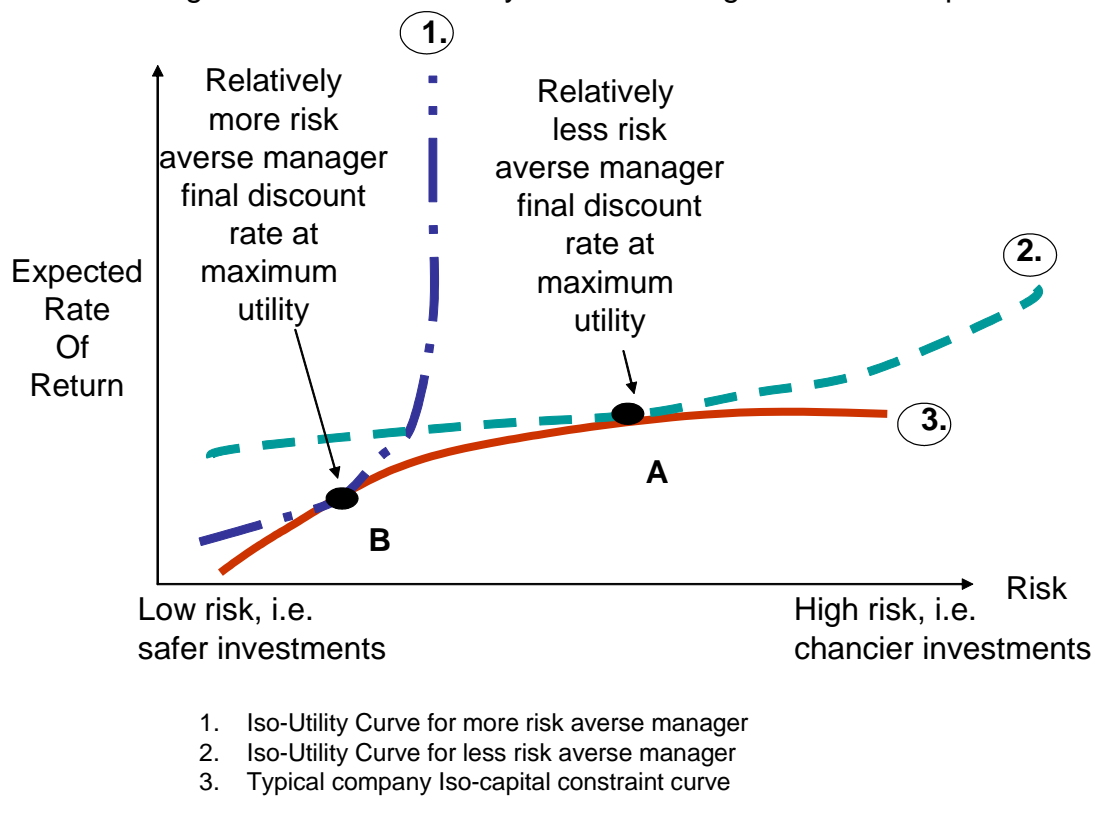


To determine if the cautious shift phenomenon occurs where a person moves from "point A" to "point B" on Figure 1 depending on whether he is choosing a bet for his own or other people's loss or gain, we test whether a player in isolation bets on his own potential gain differently from how he bets on other people's potential gain. The difference in having potential gains for the player versus having potential gains for others is likely to cause a shift in how much risk the player will take. This is different from Beard and Beil (1994) where negative outcomes are incorporated in their study. In our experiment, when the person chooses for the benefit of others in the group there is neither punishment nor reward but just the knowledge that the others won more or less, i.e. the player doesn't win more money along with the group. Such a situation is very a propos to a government-owned business, since its managers are bureaucrats who will likely not directly benefit in the outcomes of decisions they make, but who must nevertheless decide risk for other's losses or gains. Since many government-owned businesses are often monopolies that have a single manager or board entity in charge and no competition, the manager may take fewer risks than he would take if all the gains were for himself, or if there were competitors that could take away market share if nothing is done.

Such a government-owned entity has to make risky decisions that involve large payoffs or losses to the country, or in the case of a large firm to the stockholders. But unlike the environment of the risky shift phenomenon, these risky decisions about business development will be made in isolation by the bureaucrats or managers away from the political mêlée. Their decisions may not affect their own personal welfare. Nevertheless, eventually the decision will be revealed and the person making the decision will be held accountable. Therefore, rather than an individual or group making a decision in a crowd or with a lot of fanfare as in the original Risky Shift Phenomenon, now the individual decision maker must make his decision in isolation but still knows that the decision will be revealed in time. In that case the decision maker may be reluctant to take risks that could potentially cause a loss of money to the government and the people of the country or to stakeholders of a large corporation because they want to avoid any criticism. In a public setting like a game show with people yelling at you what to do, you can easily rationalize a loss due to the fact that you were doing what the crowd wanted you to do. However, a decision in private that is revealed later carries the burden that only the decision maker will bare. In fact Sniderman et. al. (1991) show decision makers become more risk averse when they expect their choices to be reviewed by others.

To test the hypothesis that decision makers become more risk averse when they must decide over other people's potential gain or loss, an experiment was set up. In the first experiment an individual has the choice of taking a risk with a given payoff for his own benefit or not taking a risk at all for a guaranteed benefit. In a second experiment, the very same individual is asked to make the same risk decision but this time for the benefit of a group of other people and not for him or herself. Results showed that when they chose for themselves individuals took greater risks for their own personal gain, but when given the same choice for the gain or loss of others, the subjects had a cautious shift and became relatively more risk averse.

As mentioned above, a second experiment with higher pay-offs provided an alternative analysis. We found that with higher payoffs, there was no shift whatsoever between decisions for oneself and decisions for others. A full discussion of these results is given below in Section 4 Data and Results. The overall results though may explain why some government-owned companies are not aggressively expanding their business as they might otherwise do in the private sector since they are risk averse to new investments. Risk aversion may be creating an impediment for starting new projects.

\section{GAME SET UP}

One option to determine risk aversion for one's self and for decisions for the sake of others is to use a Holt and Laury (2002) approach where subjects make a series of decisions to show their own attitude towards risk and are then offered the chance to make the same decisions for others' benefit as well. One criticism of this approach is that by having a series of decisions, it may cause subjects to change their risk attitudes mid-experiment. The first decision in the set may affect the second decision etc. Even if the sequence is reversed, the experience of deciding may change someone's attitudes. While the Holt and Laury approach looks to be a classic risk analysis method, the Charness and Jackson experiment of a single decision looks to be a good alternative approach to see if risk attitudes 
change. In this paper, we present results from an experiment where a single decision was made for oneself, and a single decision was made for the benefit of others.

In the first experiment an individual had the choice of taking a risk with a given payoff for his own benefit or not taking a risk at all for a guaranteed benefit. In a second experiment, the very same individual was asked to make the very same risk decision but this time for the benefit of a group of other people. Results showed that when participants chose for themselves, the majority of them took the risk of trying to win more money, giving up the guaranteed money. However when given the exact same choice to make for the potential gain of others, the majority of the subjects became more risk averse and more often took the guaranteed money for the others.

Students from economics principles, business, biology and other classes were randomly assigned to groups of 4 to 6 . Participants' ages varied in line with typical undergraduate classes and included members of both sexes. The decision to place certain people into a group was arbitrary. Each group was put into a room. Each participant in the group drew a pen to randomly chosen the first to participate. All the pens drawn were exactly the same except one, which had a hidden mark on it. The person who drew that pen became the decision maker but did not know that he or she would be the only decision maker. Nothing was explained to the group about the experiment except that a disclaimer was read thanking them for participating and that they could win up to $\$ 25$.

The single individual decision maker was then taken into a betting room where he was given a choice. The first option was to take a $\$ 10$ payoff with total certainty for himself. The second choice was to relinquish the certain $\$ 10$ and roll two dice for a chance to win $\$ 25$. Rolling a $2,3,4,5,6$, or a 7 , won the student $\$ 25$. If he rolled an 8 , $9,10,11$ or a 12, though, he lost everything, and received no money at all. Each participant was informed that the probability of winning the $\$ 25$ was $58 \%$; the probability of losing was $42 \%$, and each was informed how rolling the dice achieved that probability. Therefore the expected value of the bet also explained to the subject was $\$ 25 \times 0.58$ $=\$ 14.5$ compared to the certain payoff of not taking the bet of $\$ 10$, which was explained. When each participant entered and was told his choice, $74 \%$ of the participants choose to roll the dice for the higher valued prize and gave up the sure $\$ 10$. Once the participant decided what to do, he either rolled the dice or did not depending on his choice. After the play, he received or was promised in writing his individual winnings.

Next the participant was told that no other player from his group was going to play the game, but that he was going to have to represent the other members of the group. As the group representative, that player was going to make the same decision that he had just made for himself for all of the other members of his group. That is, he was going to decide whether the other group members would get a sure $\$ 10$ per person or give up the guaranteed cash for a chance to win $\$ 25$ per person. His own winnings were already secure and he was informed that the decision facing him would neither gain him more money nor reduce his prior earnings. The other group members did not yet know he would be making the decision for them. What is more, it was going to be the single participant making the decision in isolation and also throwing the dice (if he chose to gamble). That participant also understood that his decision would be revealed to the others when they came in. All was done in seclusion only to be revealed to the rest of the group right after all the decisions and rolls were done. Depending on how the individual choose, the game would end if he decided not to roll the dice, but if he decided to take the risk of possibly winning more cash for every group member, he would then roll the dice. At the conclusion of either choice, the group would be brought in and told the result.

One of the concerns of the above experiment was that it is not clear if the group representative is affected more by the group's average or aggregate winnings. That is, does the subject make a decision based on the average benefit (the payoff) for each member of the group or does he focus on the entire group's aggregated benefits (the payoff times $\mathrm{N}$ members)? In the experiment, we always explained the average winnings for the group, but the group size did vary from 4 to 6 . As it is we chose from the start to present the decision payoff for the participant's group in terms of the average winnings per person which we feel best represents people's understanding of how the payoff affects people in their group.

Another potential criticism encompasses order effects. According to Harrison et. al. (2005a) the order of events makes a difference in people's approach to risk. That is if you experience risk taking once, it changes your risk behavior. Therefore, if a participant decides to take a risk for the group before doing so for himself, that will 
make a difference in his risk preference. However there are two problems with changing the order in our experiment, one is group cohesion and the other is payment.

We put the entire group together at first to create a sense of community so that at the very least, the group representative had a mild interest in maximizing the groups well being, mimicking decision makers in the real world. Harrison et al.'s (2005a) argues that order effects (in Harrison's case about the magnitude of a prize) are a vital part of risk experiments. Thus they point out that the order can create an interaction between decision maker events. For example, the experience of taking risks and enduring the results may change your risk attitude. We account for this experience by noting whether participants change their behavior for others based on the results of their initial bet. However, in this experiment, we stress that the participants needed to be mildly interested in "their" group. Once you create a group feeling and one person is separated out, that person will still have a sense of being a part of the group. If you change the order, the participant immediately assumes that he is also going to reap the same reward that everyone else obtains. Once you explain he or she is not to receive any reward, other than a participator fee, you get the unwanted interaction of the participant not caring for the group. Therefore, if you say there is no reward for the participant, you lose group cohesion and the certainty that the participant is mildly interested in maximizing the group's well being.

The second problem is that when a decision maker makes a decision for other's in the real world, even CEOs, they are always paid first before they make a decision for others. It is almost never the case that anyone is forced to make a decision for others first, and then get paid later with the risk that you may not get paid at all. Indeed CEOs, even when given stock options (which theoretically means they are making risky decisions for their own as well as other's benefits) are actually still guaranteed a pay package. As Carr (2007) says, "The oxymoron of the 'entrepreneurial manager' is shown up by safety devices such as guaranteed bonuses, severance pay, hugely generous provision if the company changes hand, perks, accelerated vesting options and massive pension contributions." So if risk taking agents are not forced to take risks first and then get paid later in the real world, there is no reason to model it in the experimental world. Thus if we find a difference between risk taking for oneself and risk taking for the sake of others, in the sequence modeled, then this gives good evidence for what is happening in the real world. Even in physics there can be differences in reactions when directions change. Magnets often exhibit hysteresis, where their pull changes when an object is dragged on top of it, but that change in magnetism does not imply that there is no magnetism.

\section{DATA AND RESULTS}

A first set of 26 student groups were run. These groups were run during and after classes and therefore the size of the groups ranged between 4 to 6 people. The groups included mostly freshmen and sophomore students of both sexes although some upper classmen and graduate students did take part. The groups were selected arbitrarily. Each group's representative player was chosen by a random draw. The results of the first set are shown in Table 1. The table shows how many players switched or did not switch from their original decision. We call betting the "risk option" and not betting the "safe option." The results show 11 of 26 players (42\%) had a cautious shift, while only 1 of 26 players (4\%) had a risky shift. Table 2 shows the results of whether the two populations, i.e. the set of bets for oneself and the set of bets for others pooled together, have the same mean or whether they have a statistically different mean. With 26 samples of data we can reject the hypothesis that they are the same at the $0.5 \%$ level. Since the mean decision to take risk for others is much less than the mean decision to take risks for oneself, this shows a tendency for greater risk aversion for decision making for the benefit of others. 


\begin{tabular}{|c|c|c|c|}
\hline \multicolumn{3}{|c|}{$\begin{array}{c}\text { Table 1: First Group of Students } \\
\text { Binomial Test: Subject Switch percentages }\end{array}$} & \multirow[b]{2}{*}{ Per Cent } \\
\hline $\begin{array}{l}\text { Choice } \\
\text { for Self }\end{array}$ & $\begin{array}{l}\text { Choice } \\
\text { for } \\
\text { Others }\end{array}$ & Number & \\
\hline Risk & Safe & 11 & $42 \%$ \\
\hline Risk & Risk & 8 & $31 \%$ \\
\hline Safe & Safe & 6 & $23 \%$ \\
\hline Safe & Risk & 1 & $4 \%$ \\
\hline \multicolumn{2}{|l|}{ Sample Size } & 26 & \\
\hline \multicolumn{4}{|c|}{ Note: The same subjects did both tests } \\
\hline
\end{tabular}

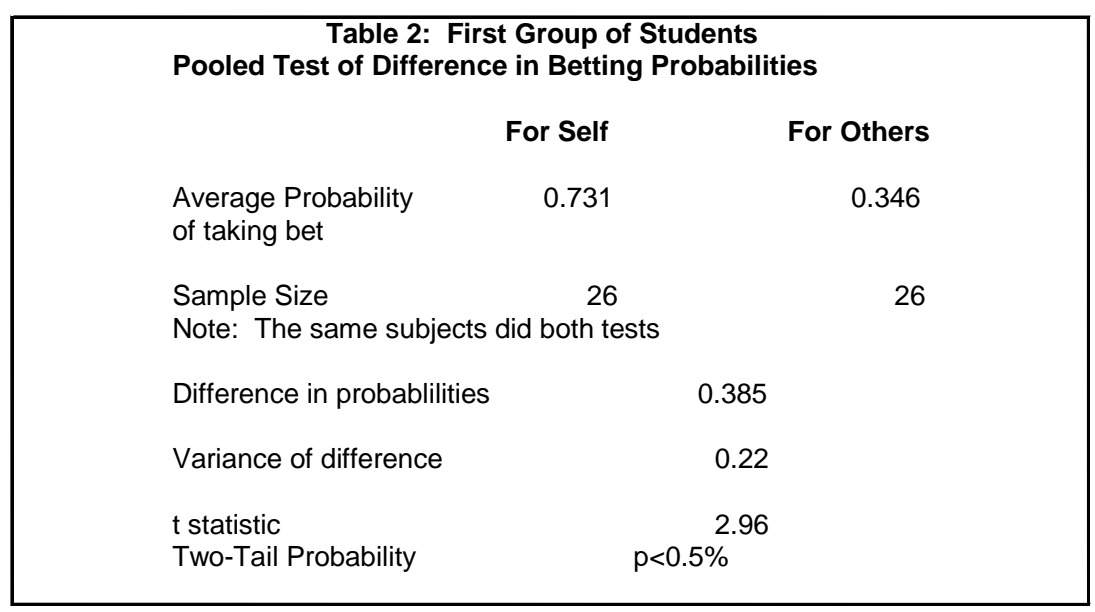




\begin{tabular}{|c|}
\hline $\begin{array}{c}\text { Table 3: First Group of Students } \\
\text { Correlation of winning for self to betting for others }\end{array}$ \\
\begin{tabular}{cc}
\hline Win Self Bet Others \\
\hline Bet Others & 0.08
\end{tabular} \\
\hline $\mathrm{t}=\quad \begin{array}{r}0.33 \text { Therefore there is no correlation } \\
\text { between wining the bet for oneself } \\
\text { and betting for others } \\
\text { at 10\% level for one-tailed test }\end{array}$ \\
\hline
\end{tabular}

Table 4: Second Group of Students Binomial Test: Subject Switch percentages

$\begin{array}{llrr}\begin{array}{l}\text { Choice } \\ \text { for Self }\end{array} & \begin{array}{l}\text { Choice } \\ \text { for } \\ \text { Others }\end{array} & \text { Number } & \text { Per Cent } \\ \text { Risk } & \text { Safe } & 21 & 36 \% \\ \text { Risk } & \text { Risk } & 19 & 32 \% \\ \text { Safe } & \text { Safe } & 10 & 17 \% \\ \text { Safe } & \text { Risk } & 9 & 15 \% \\ \text { Sample Size } & & 59 & \end{array}$

Note: The same subjects did both tests

Table 5: Second Group of Students Pooled Test of Difference in Betting Probabilities

$\begin{array}{llr} & \text { For Self } & \text { For Others } \\ \begin{array}{l}\text { Average Probability } \\ \text { of taking bet }\end{array} & 0.677966 & 0.474576 \\ \begin{array}{l}\text { Sample Size } \\ \text { Note: The same subjects did both tests }\end{array} \\ \text { Difference in probabilities } & 0.203 \\ \text { Variance of difference } & 0.238 \\ \text { t statistic } & 2.32187 \\ \text { Two-Tail Probability } & p<5 \%\end{array}$

Table 6: Second Group of Students Correlation of winning for self to betting for others

\begin{tabular}{ccr}
\hline & Win Self Bet Others \\
\hline Win Self & 1 & \\
\hline Bet Others & 0.08 & 1 \\
\hline
\end{tabular}

$t=\quad 0.47$ Therefore there is no correlation between wining the bet for oneself and betting for others

at $10 \%$ level for one-tailed test 
However it may be the case that if one wins or loses in the initial bet for oneself, that will in some way taint how one bets for others. So in Table 3 the correlation is tested whether winning the bet for yourself induces a greater probability to bet for others. The correlation there tests false. There is no correlation between winning the first bet and taking the second bet. The t-statistic for the correlation test is too low to be able to reject the null hypothesis that there is no correlation between the two.

After the first run of the experiment was finished, we received a second grant which allowed us to re-run the experiment. We did so and managed to obtain 59 data sets, $90 \%$ of which were groups made up of six players arbitrarily arranged, the rest being made up of five players. The groups included members of both sexes, mostly undergraduates from freshmen to seniors and some graduate students. This time we had enough money to pay a show up fee which allowed us more flexibility to organize groups outside of class. Table 4 shows that 21 of 59 players had a cautious shift $(36 \%)$ while 9 of 59 players had a risky shift $(15 \%)$. The difference between betting for one self and betting for others was smaller in this second set, but with the higher number of data points, the difference was nevertheless still quite large as shown in Table 5. People, are more likely to bet when they are playing for themselves than when playing for the benefit of others. Table 6 , similar to Table 3 , shows that whether you win or lose, if you take the bet for yourself it does not affect your decision to take the bet for others. Table 7, 8 and 9 combine the data for both of the first two groups and again show that people are more risk averse when choosing to bet for others. Table 7 shows that 32 of 85 (38\%) total participants had a cautious shift, while only 10 of $85(12 \%)$ had a risky shift.

At this point, we wanted to try one variation so we ran a third group of students again from freshman to seniors and both sexes arbitrarily grouped together. This time we raised the stakes just as in the study by Holt and Laury (2002) did. We changed the winnings for a successful gamble from $\$ 25$ to $\$ 50$. We changed the guaranteed value of not betting from $\$ 10$ to $\$ 20$. This changed the results. Table 10 shows the results and now there is surprisingly no difference between people who exhibit a cautious shift, 9 of 42 for $21 \%$, versus people who exhibit a risky shift, again 9 of 42 people for $21 \%$. This then is similar to Harrison et. al. (2005b). Table 11 shows that there is no difference between people taking the bet for oneself and taking the bet for others. Decisions are very close to $50 / 50$, that is there is about a 50/50 chance people will take the bet for themselves and a 50/50 chance they will take the bet for others. Interestingly, the probability of choosing to bet became close to the probability of winning a bet, i.e. $58 \%$ for a win and $42 \%$ for a loss. We also tested to see if there was a difference between groups 1 and 2 and group 3, but found the data too small to test the differences in the decisions for oneself or test differences in the decisions for the benefit of others.

We might speculate though that with higher values for the non-betting options, i.e. the guaranteed $\$ 20$ for not betting, that that extra money was enough to tip individuals who would normally bet, to becoming more risk averse and not betting. However why would the same $\$ 20$ not also cause the people to bet even less for the benefit of others? Clearly the higher level of betting adds pressure to the decision maker and it may be that people are concerned, as they often told us during the experiments, of what others would think of them. One hypothesis that could be pursued is that the genetic make up of individuals affects their risk preference. Some neurological studies suggest that the brain make up affects how we relate to others and how much risk we normally take. The higher value payoffs may trigger a different response to risk and the relationship to others. See Kosfeld (2007), Berg et. al. (1995) and Kreek et. al. (2005). Also Baker II, Laury and Williams (2007) show that groups are more likely than individuals to choose a safe lottery in low winning percentages, but less likely to choose the safe lottery in high winning percentages.

Interestingly, we found here a marginally significant correlation between winning a bet and taking the bet for others. Table 12 shows that there is a small correlation between winning the bet for yourself and making the bet for others. Possibly with more money on the line, people are more likely to be influenced by the results of their initial bet, if they made one. In other words, even though a participant may say that they believe the dice are fair, sub-consciously if he wins a high stakes bet, he may believe that he will win again. i.e. that there is some skill involved. A low stakes bet doesn't affect him as much. This suggest that it is possible that with more experience, decision makers that have had a big loss at one point will afterwards be more risk averse than decision makers who have yet to lose big. For example, Jablonowski (2006) shows that experienced oil drilling platform managers in the Gulf of Mexico are quicker to evacuate the platform when a hurricane comes than inexperienced managers, i.e. experience of large risks, e.g. one's own life, leads to caution. 


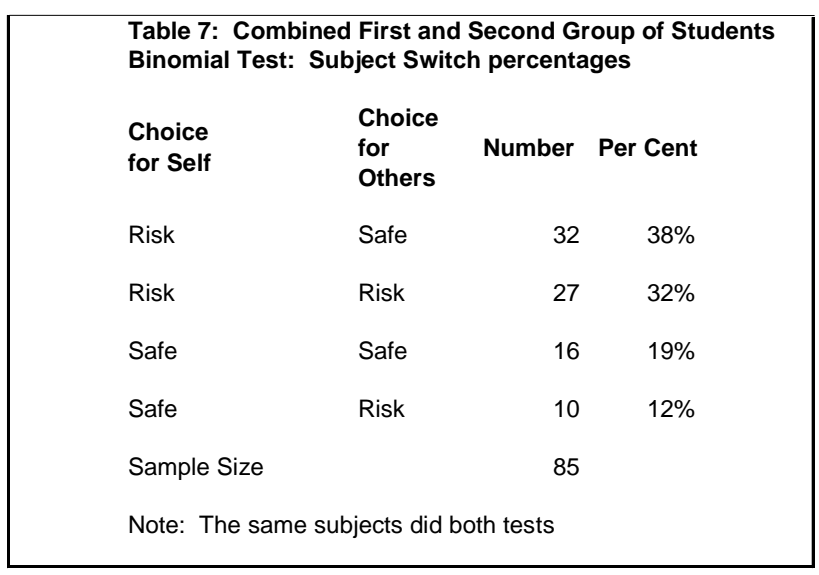

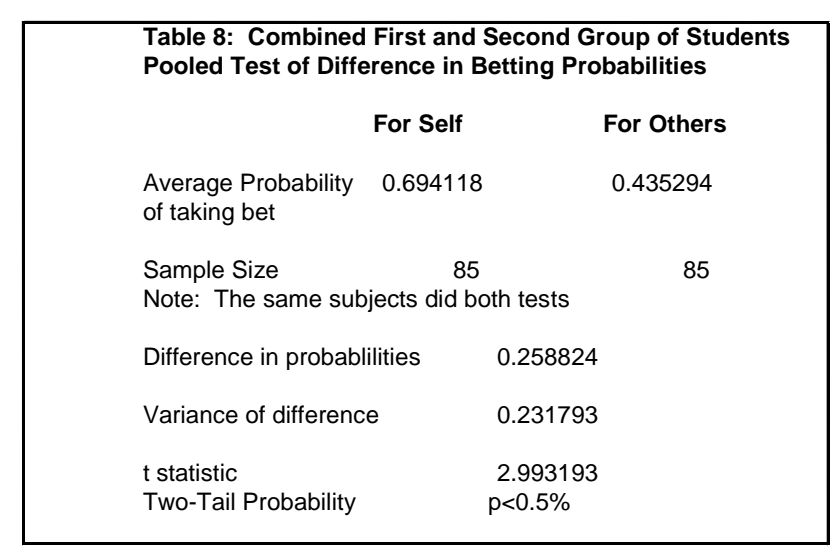




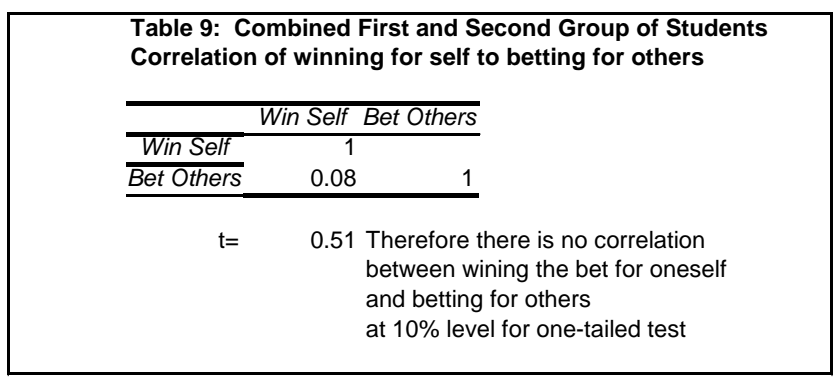

\begin{tabular}{|c|c|c|c|}
\hline \multicolumn{4}{|c|}{$\begin{array}{l}\text { Table 10: Third Group of Students (High payoff) } \\
\text { Binomial Test: Subject Switch percentages }\end{array}$} \\
\hline $\begin{array}{l}\text { Choice } \\
\text { for Self }\end{array}$ & $\begin{array}{l}\text { Choice } \\
\text { for } \\
\text { Others }\end{array}$ & Number & Per Cent \\
\hline Risk & Safe & 9 & $21 \%$ \\
\hline Risk & Risk & 15 & $36 \%$ \\
\hline Safe & Safe & 9 & $21 \%$ \\
\hline Safe & Risk & 9 & $21 \%$ \\
\hline \multicolumn{2}{|l|}{ Sample Size } & \multicolumn{2}{|l|}{42} \\
\hline \multicolumn{4}{|c|}{ Note: The same subjects did both tests } \\
\hline \multicolumn{4}{|c|}{$\begin{array}{l}\text { Table 11: Third Group of Students (High payoff) } \\
\text { Pooled Test of Difference in Betting Probabilities }\end{array}$} \\
\hline \multicolumn{3}{|c|}{ For Self } & For Others \\
\hline \multicolumn{3}{|l|}{$\begin{array}{l}\text { Average Probability } \\
\text { of taking bet }\end{array}$} & 0.571429 \\
\hline \multirow{2}{*}{\multicolumn{3}{|c|}{$\begin{array}{l}\text { Sample Size } \\
\text { Note: The same subjects did both tests }\end{array}$}} & 42 \\
\hline & & & \\
\hline \multicolumn{2}{|c|}{ Difference in probablilities } & \multicolumn{2}{|c|}{0} \\
\hline \multicolumn{2}{|c|}{ Variance of difference } & \multicolumn{2}{|c|}{0.251} \\
\hline \multicolumn{2}{|l|}{ t statistic } & \multirow{2}{*}{\multicolumn{2}{|c|}{0}} \\
\hline Two-Tail Probability & & & \\
\hline
\end{tabular}

Table 12: Third Group of Students (High payoff) Correlation of winning for self to betting for others

\begin{tabular}{ccr}
\hline & Win Self Bet Others \\
\hline Win Self & 1 \\
Bet Others & 0.324 & 1 \\
\hline
\end{tabular}

$\mathrm{t}=\quad 1.61$ Therefore there is some correlation between wining the bet for oneself and betting for others at $10 \%$ level for one-tailed test 
On the other hand, there is anecdotal evidence that individual entrepreneurs go out and take big risks, lose big, but then go out again and take big risks all for their own benefit. Columbus "Dad" Joiner, the Texas wildcat oil driller who found the great East Texas oil field was one such entrepreneur (Yergin 1991). However, most government workers got into government by not taking risk and by desiring a steady, less risky job.

What Tables 1 through 12 show is that the level of risk-taking by people for their own benefit is often higher than the level of risk-taking that people take for the benefit of others, that is there is a cautious shift for decisions for others. More to the point, people are relatively less risk averse for their own benefit and become relatively more risk averse when they have to make a choice for the benefit of others. While the results for the higher payoff show no-difference in risk taking, they still at least show that there is not a greater incidence of risk taking for the benefit of others than for oneself. Plus the experience of a win or a loss tends to affect decision making for higher payoffs. Since the tendency was for the safer, guaranteed money for others, it looks as though the decision makers were relatively more risk averse to others potential loss of the guaranteed money. The evidence suggests that bureaucrats in a government-owned company or even decision makers in a relatively large corporation can be risk averse to investing in new business opportunities.

There is also anecdotal evidence that this relatively greater risk averse behavior for the benefit of others occurs in the real world. For example Sowell (2004) shows how protectionism for industries in India caused the Hindustan Motor Corporation to have no innovation in their cars for over 30 years. Innovation both requires the risk to experiment and the risk to take redesigned products into the market place. The Hindustan Motor Corporation didn't have to take the risk of implementing innovation, which could have incurred greater costs, since it knew there was no competition, and so it would not lose market share by not taking any risks. Therefore risk taking, or the lack thereof, plays a huge role in any decision process no matter the specific engineering characteristics or complexity. This is exactly what Ellman and Kontorovich (1992) say caused the fall of the Soviet Union-a lack of innovation, i.e. a lack of risk taking.

Further research on this subject might include having a recurring decision to roll the dice for oneself several times to see if risk taking changes with experience, and have a recurring decision to roll the dice for the rest of the group to see if risk taking for others also changes with experience. This would be different than the Holt and Laury method where several different risk decisions are made in sequence because the Holt and Laury method only has a payoff after all the sequence of decisions are made. What we are talking about is having a participant make a decision and then experience the payoff to others, then make another decision and then experience that payoff to others, etc. If participants had to choose a risky or safe bet for others on a recurring basis, and be present as the group is rewarded or not on each subsequent round, then they might tend to become even more risk averse over time as they inevitably experience a loss as the Jablonowski evidence suggests. Based on some anecdotal evidence, a higher level of caution could occur if the game was repeated for one decision maker since the people in the group affected by the decision maker sometimes would say things like, "you should have taken the safe bet." A few asked why decision makers didn't bet when they were cautious, although most participants were happy with whatever the decision maker decided. Nevertheless, it may be the case that negative experience with risky outcomes can enhance the cautious shift.

\section{CONCLUSIONS}

In this paper, the effect of making decisions for oneself and for the benefit of other people was looked at and it was found that people are more willing to take risks for themselves and less willing to take risks for the benefit of others. That is, there is a cautious shift between the decisions that involve the potential gain for oneself versus the potential gain for others. The difference in the ratio of taking a bet for one's own gain and for the gain of others is significant and substantial at lower stakes.

This risk averse behavior may happen at government-owned corporations or very large publicly traded corporations as well. Anecdotal evidence (Sowell 2004 and Helfand et. al. 2007) suggests that many governmentowned corporations or very large corporations invest less in new innovations as opposed to smaller companies where more innovation occurs. The fact that smaller companies are more prone to riskier decision-making behavior or wiliness to innovate lies in the need to survive the competitive market place. The behavior of those people 
making decisions for the benefit of others may be affected by risk aversion. This may be one reason why government owned companies and even some large publicly traded corporations do not aggressively enter new markets or expand their business.

\section{ACKNOWLEDGEMENTS}

This research was supported by a major grant from Flint Hills Resources, a wholly owned subsidiary of Koch Industries, Inc., to the University of Alaska Fairbanks.

\section{AUTHOR INFORMATION}

Dr. Douglas B. Reynolds is associate professor of oil and energy economics at the University of Alaska Fairbanks. He has lived in Alaska for over ten years and has extensive experience in Alaska's and the world's oil, natural gas and energy industries.

He was an energy consultant for the State of Alaska Legislature, and Alaska's State Department of Revenue in the spring of 2002 and the winter of 2005 to 2006. He was also an assistant professor in economics from 1995 to 1997 in Kazakstan's Institute of Management, Economics and Strategic Research (KIMEP), in Almaty, the Republic of Kazakstan.

Professor Jacob Joseph is in the Business Administration department at the School of Management, University of Alaska Fairbanks (1991 - Present). He teaches Human Resources, Compensation, Org Behavior and has a research interest in Career Plateauism and Ethical Issues. Dr. Joseph has many journal articles and chapters in a number of peer reviewed academic journals. His paper, "Social desirability: The Role of Over-Claiming, Self-Esteem, and Emotional Intelligence," in Psychology Science was well received.

Mr. Reuben Sherwood was a graduate student at the University of Alaska Fairbanks. He helped run experiments and researched the paper. Mr. Sherwood has lived and worked in Alaska his whole life and has researched bridge technology and economics for spanning the Anchorage Turnagain Arm.

\section{REFERENCES}

1. Baker II, Ronald J., Susan K. Laury and Arlington W. Williams. (2004) "Comparing Group and Individual Behavior in Lottery-Choice Experiments," September 20, CAEPR Working Paper No. 2007-018.

2. Beard, T. Randolph, and Richard O. Beil Jr. (1994) "Do People Rely on the Self-Interested Utility Maximization of Others? An Experimental Test," Management Science, 40252-262.

3. Berg, Joyce, John Dickhaut and Kevin McCabe (1995). "Trust, Reciprocity, and Social History," Games and Economic Behavior, Volume 10, Issue 1, July 1995, Pages 122-142.

4. Chakravarty, Sujoy, Glenn A. Harrison, Ernan E. Haruvy and E. Elizabet Rutström (2005) "Are you risk averse over other people's money?" Working paper, Indian Institute of Management, Ahmedabad, India.

5. Charness, Gary and Matthew O. Jackson (2007). "The Role of Responsibility in Strategic Risk-taking," Working paper, UC Santa Barbera and California Institute of Technology.

6. Ellman, Michael and Vladimir Kontorovich (1992) "Overview," in The Disintegration of the Soviet Economic System, Michael Ellman and Vladimir Kontorovich (eds.) New York: Routledge, pp. 1- 39.

7. Friedman, Milton and Leonard J. Savage, (1948). "The Utility Analysis of Choices Involving Risk" Journal of Political Economy, August, Volume 56.

8. Harrison, Glenn W., Eric Johnson, Melayne M. McInnes, and E. Elisabet Rutstrom, (2005a). "Risk aversion and Incentive Effects: comment," American Economic Review, June pp. 897 - 901.

9. Harrison, Glenn W., Morten Igel Lau, E. Elisabet Rutstrom and Marcela Tarazona-Gomez, (2005b). "Preferences over Social Risk," University of Central Florida Working Paper No. 05-06.

10. Helfand, Jessica, Akbar Sadeghi and David Talon (2007). "Employment Dynamics: Small and Large Firms over the Business Cycle," Monthly Labor Review, March 2007, U.S. Bureau of Labor Statistics.

11. Holt, Charles A. and Susan K. Laury (2005) "Risk Aversion and Incentive Effects: New Data without order effects," American Economic Review, 95(3) pp. 897 - 901. 
12. $1644-55$. , (2002) "Risk Aversion and Incentive Effects," American Economic Review, 92(5) pp.

13. Jablonowski, Christopher J. (2006). "Evidence on Risk Preferences in E and P Operations: Examining the Decision to Evacuate." In International Association of Energy Economics NEWSLETTER, published by IAEE, second quarter, 2006.

14. Kahneman, Daniel, and Dan Lavallo (2002). "Timid Choices and Bold forecasts: A Cognitive Perspective on Risk taking," in Kahneman, Daniel and Amos Tversky (2002). Choices, Values, and Frames, edited by Daniel Kahneman, Amos Tversky. Cambridge University Press, pp. 393-413.

15. Kahneman, Daniel and Amos Tversky (2002). Choices, Values, and Frames, edited by Daniel Kahneman, Amos Tversky. Cambridge University Press.

16. Kogan, Nathan and Michael A. Wallach, (1964). Risk-Taking: A Study in Cognition and Personality, New York, Holt, Rinehart, Winston.

17. Kowert, Paula and Margaret G. Hermann (1997). "Who Takes Risk? Daring and Caution in Foreign Policy Making," Journal of Conflict Resolution, 41:5 pp. 611-637.

18. Kosfeld, Michael, (2007). "Trust in the brain. Neurobiological determinants of human social behavior," The EMBO Journal, EMBO reports, volume 8, S1, S44-S47 doi:10.1038/sj.embor.7400975.

19. Kreek, Mary Jeanne, David A Nielsen, Eduardo R Butelman \& K Steven LaForge, (2005). "Genetic influences on impulsivity, risk taking, stress responsivity and vulnerability to drug abuse and addiction." Nature Neuroscience 8, 1450 - 1457 (2005) Published online: 26 October 2005; | doi:10.1038/nn1583

20. Levine, J.M. and R.L. Moreland (1998). "Small groups,” In D. Gilbert, S. Fiske, \& G. Lindzey (Eds.), The handbook of social psychology (4th ed.). Boston, MA: McGraw-Hill.

21. March, James G. and Zur Shapira (1987) "Managerial Perspectives on Risk and Risk Taking," Management Science, Vol. 11, No. 11, November 1987, pp. 1404-1418.

22. Markowitz, Harry (1952). “The Utility of Wealth,” Journal of Political Economy, 60 April, pp. 151 -158.

23. Miller, D. and M. Ross (1975). "Self Serving Biases in Attribution of Causality: Fact or Fiction?" Psychological Bulletin, vol. 82, pp. 213-225.

24. Newendorp, Paul, and John Schuyler (2000). Decision Analysis for Petroleum Exploration, $2^{\text {nd }}$ Edition, Planning Press, Aurora, Colorado.

25. Ramsey, J. (1980). Bidding and oil leases. Greenwich, CT: JAI Press.

26. Sniderman, Paul M. Richard A. Brody, and Philip E. Tetlock, (1991). Reasoning and Choice, Cambridge: Cambridge University Press.

27. Sorrentino, R.M, E.C. Hewitt and Raso-Knott P.A., (2005). "Risk-taking in games of chance and skill: individual differences in affective and information value," Journal of Personality and Social Psychology, vol. 62 , pp. 522-533.

28. Sowell, Thomas, (2004). Basic Economics, a Citizens' Guide to the Economy, revised and expanded edition, pp. 80-81.

29. Stoner, J. A. F. (1961). A comparison of individual and group decisions involving risk. Unpublished Master's Thesis, Massachusetts Institute of Technology.

30. Swalm, R.O. (1966). "Utility Theory: Insights into Risk Taking," Harvard Business Review, Vol. 44, pp. 123-136.

31. Viscusi, W. Kip, Wesley A. Magat, and Joel Huber, (1987). "An Investigation of the Rationality of Consumer Valuations of Multiple Health Risks," RAND Journal of Economics, RAND, vol. 18, no.4, pages 465-479.

32. Ward, Michael R. (1992). "Drug Approval Overregulation,” Regulation, CATO institute, Volume 15, Number 4.

33. Wallach, M. A., N. Kogan and D. J. Bem, (1962). "Group influence on individual risk taking." Journal of Abnormal and Social Psychology, vol. 65, pp. 77-86.

34. Yergin, Daniel (1991). The Prize, The Epic Quest for Oil, money and Power, Touchstone New York. 


\section{NOTES}

